\title{
End-Users' Product Preference Across Three Multipurpose Prevention Technology Delivery Forms: Baseline Results from Young Women in Kenya and South Africa
}

\author{
Rachel Weinrib $^{1}$ (D) Alexandra Minnis ${ }^{1,2}$ - Kawango Agot $^{3} \cdot$ Khatija Ahmed $^{4}$. \\ Fred Owino $^{3} \cdot$ Kgahlisho Manenzhe $^{4} \cdot$ Helen Cheng ${ }^{1}$ Ariane van der Straten ${ }^{1,5}$
}

Published online: 20 October 2017

(c) The Author(s) 2017. This article is an open access publication

\begin{abstract}
A multipurpose prevention technology (MPT) that combines HIV and pregnancy prevention is a promising women's health intervention, particularly for young women. However, little is known about the drivers of acceptability and product choice for MPTs in this population. This paper explores approval ratings and stated choice across three different MPT delivery forms among potential end-users. The Trio Study was a mixed-methods study in women ages 18-30 that examined acceptability of three MPT delivery forms: oral tablets, injections, and vaginal ring. Approval ratings and stated choice among the products was collected at baseline. Factors influencing stated product choice were explored using multivariable multinomial logistic regression. The majority (62\%) of women in Trio stated they would choose injections, $27 \%$ would choose tablets and $11 \%$ would choose the ring. Significant predictors of choice included past experience with similar contraceptive delivery forms, age, and citing frequency of use as important. Ring choice was higher for older (25-30) women than for younger (18-24) women $(\mathrm{aRR}=3.1 ; \mathrm{p}<0.05)$. These results highlight the
\end{abstract}

Rachel Weinrib

rweinrib@rti.org

1 Women's Global Health Imperative, RTI International, 351 California St Suite 500, San Francisco, CA 94104, USA

2 School of Public Health, University of California, Berkeley, CA, USA

3 Impact Research and Development Organization, Kisumu, Kenya

4 Setshaba Research Centre, Soshanguve, South Africa

5 Department of Medicine, Center for AIDS Prevention Studies, University of California San Francisco, San Francisco, CA, USA importance of familiarity in MPT product choice of potential for variations in MPT preference by age.

Keywords Multipurpose prevention technologies . Acceptability · End-user research · HIV prevention . Product preference

\section{Background}

Preventing HIV and unintended pregnancy are key health priorities for women, particularly in sub-Saharan Africa (SSA), where rates of HIV infection are at least twice as high among young (ages 18-30) women as among young men, and 59\% of people living with HIV are women [1]. Likewise, in SSA, 40-60\% of pregnancies are unintended [2-5].

Multipurpose prevention technologies (MPTs) are biomedical interventions that provide protection from both sexually transmitted infections, such as HIV, and unintended pregnancy. A dual-purpose product that combines HIV and pregnancy prevention could offer advantages over single-indication products. In recent population-based surveys, 4 in 10 women in Kenya and 89\% of women ages 18-24 in South Africa were current users of modern contraceptive methods $[6,7]$. A contraceptive product that also confers protection against HIV could lead to greater coverage of prevention methods in these countries than a single-purpose HIV prevention method. Women may face fewer barriers to using an MPT than an HIV prevention product, including community stigma around HIV, inconsistent adherence due to the need to use two prevention products, and challenges in communicating about HIV prevention with their partners $[8,9]$. However, these MPT products will only be effective in reducing rates of HIV and 
unintended pregnancy if they are acceptable to the women who most need them.

In recent years, gaining a better understanding of enduser acceptability has emerged as a crucial component of research on new HIV prevention products for women. Acceptability among potential end-users is an important driver of product uptake, adherence (initiation and correct use), and persistence or continuation [10, 11]. Several promising HIV prevention products have failed to show effectiveness in large phase III trials conducted in Africa. These results are explained in part by low adherence to product use among trial participants, particularly among young women who comprise a key priority population for HIV and pregnancy prevention [12-14]. Adherence challenges emphasize with greater urgency the need to conduct acceptability research with young women to inform product development and roll out. Ultimately, incorporating end-user input will maximize the chances that technologies that move forward into efficacy trials, and eventually become available prevention options, are adopted and used correctly and consistently by young women.

Factors affecting prevention product choice and acceptability have been explored in many studies. In this body of research, acceptability has been conceptualized more broadly than attitudes toward the specific features of a product. Contextual factors related to the individual enduser, such as education and socioeconomic status, play an important role as predictors of acceptability, choice, and uptake $[15,16]$. Multiple dimensions of acceptability for microbicides and oral pre-exposure prophylaxis (PreP) have been described. Mensch, et al. [11], proposed a conceptual model in which product choice is informed by product acceptability factors, based on product features, and influencing factors centered on the end-user and her social context. This conceptual framework underlies the research questions that informed the design of the TRIO Study, a prospective clinical acceptability study focusing on three placebo MPT delivery forms among young women aged 18-30 years: oral tablets, vaginal ring, and injections. The TRIO Study, conducted in Kenya and South Africa, targets a gap in knowledge regarding acceptability of MPTs. The research focuses on relative preference of three product delivery forms that could support a MPT indication, by testing uptake, use, choice, and preference based on women's actual experiences with the products.

The three placebo delivery forms chosen for the TRIO Study represent promising potential MPTs as they capitalize on effective contraceptive methods already widely used by women, and reflect directions currently pursued with HIV and MPT products currently under development. All three are relatively advanced as HIV prevention methods in the product development pipeline, with the ring having completed phase III trials [17, 18], injections currently undergoing clinical trials [19], and oral PrEP tablets recently approved for use in both Kenya and South Africa [20, 21]. This paper examines product preferences before using an MPT, reflecting a real-world situation in which potential end-users would need to choose between a menu of different MPT products at a clinic or pharmacy.

\section{Methods}

The TRIO Study was a multicomponent mixed-methods study that examined acceptability of three potential multipurpose prevention technology (MPT) delivery forms: daily oral tablets, two monthly injections, and a monthly vaginal ring. Here we report baseline results from the clinical component of TRIO a prospective randomized study in which women tried each product for one month and then chose one product to use for 2 months.

\section{Study Products}

Because the goal of the study was to investigate acceptability and use of each delivery form, uncoupled from potential side effects or effectiveness, only placebo products were used. The delivery forms are shown in Fig. 1. The MPT tablets, injections, and vaginal ring were represented by placebo Truvada (to represent a co-formulated oral tablet), two $2 \mathrm{~mL}$ saline injections, one in each gluteal muscle (placebo injections used in the phase III HPTN-076 trial [22]), and the silicone elastomer placebo vaginal ring developed by the International Partnership for Microbicides (used in the phase III MTN-020 ASPIRE and IPM ring studies [17, 23]), respectively. The MPT injections were presented with a monthly dosing regimen for the TRIO study with the possibility of the active product being given once every 2 months in the future. The MPT tablet, represented by placebo Truvada, was presented with a daily dosing requirement. The ring was presented with a requirement of being inserted in the vagina continuously for 1 month and then removed and replaced with a new ring.

\section{Eligibility and Recruitment}

The clinical component of the study enrolled 277 sexually active, non-pregnant, HIV negative women ages 18-30 in Kisumu, Kenya and Soshanguve, South Africa. Study enrollment took place between December 2015 and June 2016. To be eligible for the study, women could not have participated in any prior HIV-prevention or MPT product trials or other demonstration studies.

Participants were recruited from peri-urban communities surrounding the research clinics using community 

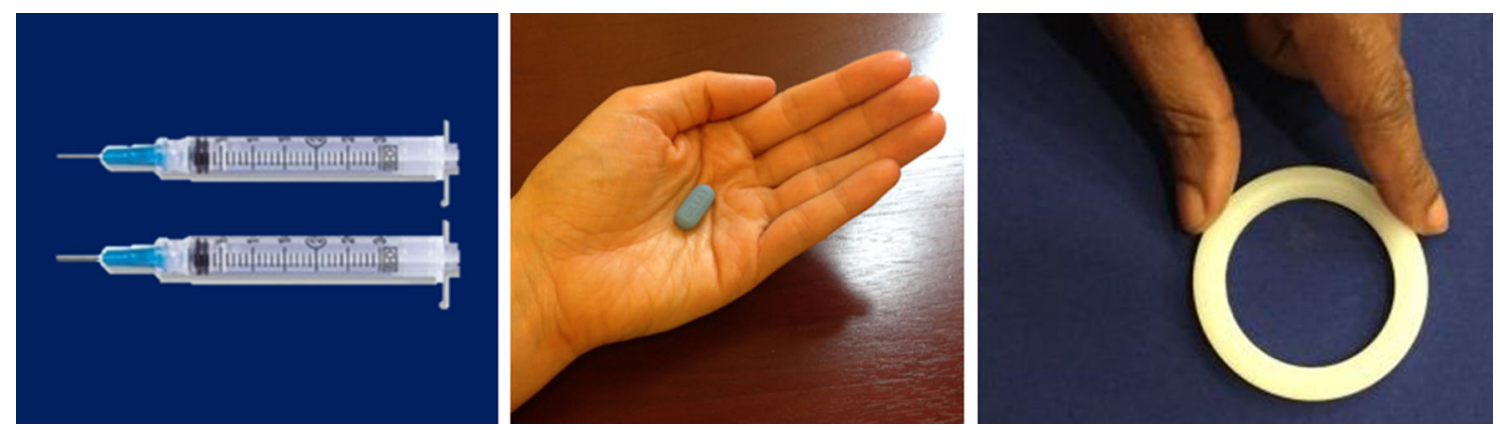

Fig. 1 TRIO Study Products

mobilization and sensitization meetings, street recruitment from shopping areas, and (in South Africa only) outreach at family planning clinics and voluntary HIV counseling and testing centers. A major consideration in the study's recruitment procedures and design was the goal of minimizing social desirability issues in reporting, such as feeling ashamed to admit nonuse or difficulty using study products, faced by other HIV prevention studies [24]. To this end, we designed multiple approaches to achieve high participant engagement in the research and encourage participation as an opportunity to contribute as a "co-designer" in the process of product development. Introductory engagement workshops, lasting around $2 \mathrm{~h}$, were conducted with groups of approximately 15-30 women prior to screening visits. The content of the workshops encouraged women to view themselves as research partners and co-designers in the study, framed the study participants as a key source of feedback for product developers, and emphasized the value of honest feedback on the products, including their dislikes and negative experiences.

\section{Procedures}

Prior to the start of the clinical acceptability study, we conducted formative interviews with 15 young women from the target population at each site, including cognitive interviewing techniques, to pretest product attribute descriptions and rating and ranking questions planned for the main study. Formative findings increased confidence that participants would comprehend the various acceptability questions, and provided insight into which product attributes were salient for these women when considering different prevention options.

To capture study-naïve product acceptability at the clinical study baseline visit, women were first shown images of the three TRIO products with minimal explanation from the interviewers. They were then asked to provide their opinions, preferences, and stated (hypothetical) product choice among the three products, using a standardized survey. Next, participants watched a brief animated educational video that explained how to use each product, including dosing frequency, and answered a subsequent set of identical questions to measure whether additional product information provided through the video changed their opinions. The video was intended to play the role of a provider who would briefly explain at the clinic how the products work. We used the format of a brief video to ensure the information would be standardized across all participants.

At the start of the acceptability questionnaire, participants were asked to imagine that they were at risk of having an unplanned pregnancy and getting HIV, and to assume that the TRIO products provided the same level of protection as condoms. Women also completed detailed demographic questionnaires at the baseline visit. Participants were then randomly assigned to one of six productuse sequences, and returned to the clinic to complete acceptability questionnaires each month. This paper presents results drawn from the baseline demographic and acceptability questionnaire data.

\section{Measures}

Informed by the conceptual model proposed by Mensch, et al. [11], we considered four domains of potential drivers of stated product choice within the broad areas of end-user influencing factors and product acceptability: (1) sociodemographic characteristics; (2) social context; (3) risk perception; and (4) product features (see Fig. 2).

Sociodemographic characteristics included age, educational attainment, food insecurity (based on participant report of how often in the past 4 weeks she worried she would not have enough food), parity, and religion. Worry about food insecurity was selected as a proxy socio-economic status measure due to evidence of its relationship with HIV risk factors [25, 26], and because of its variation within sites relative to other socio-economic characteristics measured, such as household assets, which tended to vary only between sites. Based on previous studies that have shown differences in preference and behavior between 
Fig. 2 Conceptual framework and domains of hypothesized factors influencing stated product preference

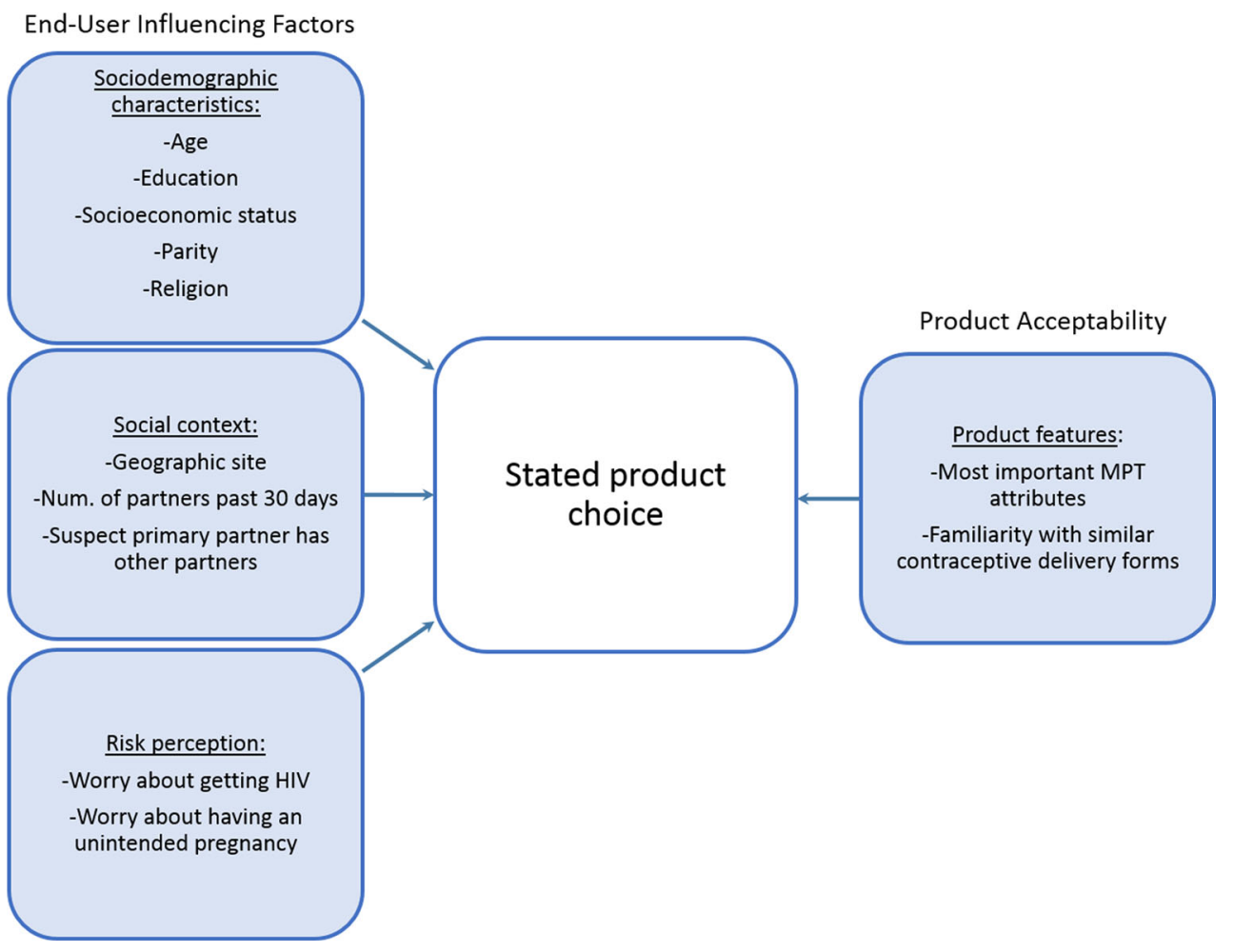

younger and older women, we hypothesized that age would be an important influencing factor for stated product choice. Age was dichotomized into two groups, ages 18-24 and 25-30, to align with the United Nations definitions of youth [27].

We considered women's perception of risk for both HIV infection and unplanned pregnancy, as measured by asking how worried they were that they might get HIV in the next 12 months, and how likely it was they would have an unplanned pregnancy in the next 12 months, respectively. Response options to these two questions corresponded with five-point Likert scales.

Hypothesized influencers in the social context domain included geographic site (Soshanguve, South Africa, or Kisumu, Kenya) and two measures related to women's partnerships: the number of sexual partners in the past 30 days; and whether they suspected their primary sexual partner had other partners.

Product features hypothesized to be influential included two factors: MPT attributes named as important, and familiarity with similar (contraceptive) delivery forms. Women were asked to free list the considerations they felt would be most important and second most important when choosing an MPT product, and responses were later coded into categories using codes generated through formative research and edited iteratively throughout the study. For this analysis, we included attributes linked to and varying across the specific delivery forms as explanatory variables: potential side effects/safety, availability/access, and frequency of use. Note that most participants who listed frequency did not specify a preference for high versus low frequency, though one woman mentioned wanting a product you don't have to take every day, and two women expressed interest in a product that would only need to be used once. Familiarity with similar delivery forms/methods was measured through prior use of long-acting reversible methods (contraceptive implants/IUD) and of injections, prior use of contraceptive pills, and experience with inserting fingers, tampons, or other materials into the vagina for any purpose in the past 3 months (an insertion procedure required for the TRIO ring).

Finally, the two outcomes examined were product approval rating and stated product choice. Product approval rating was assessed for each product by asking, "On a scale of 1-5, how much would you like (taking the tablets/receiving injections/using the ring) for both pregnancy and HIV prevention?" with response options ranging from " 1 : dislike very much" to "5: like very much". Stated choice for the tablets, injections, or ring was assessed by asking "If you could choose one of these products now to use for both pregnancy and HIV prevention, which one would it be?" Both approval rating and stated choice were collected before and after showing the educational video. 


\section{Analysis}

For all analyses, the five-point Likert-scale risk perception measures were recoded into dichotomous variables based on the distribution of responses. We described characteristics of the study sample by site, and presented product approval ratings graphically to examine the overall distributions of approval scores for each product. Next, we explored the relationship between stated choice (for the ring, tablets or injections) and various end-user and product acceptability factors hypothesized to influence acceptability using the Pearson's Chi square test. We also examined the shape of the relationship between age and product choice graphically to determine if this relationship differed between younger and older women, to ensure the appropriateness of our age categories.

Finally, we performed multinomial logistic regression analysis to calculate adjusted relative risk ratios (aRRR) of stated product choice associated with the factors hypothesized in our conceptual model to influence stated choice. Multivariable analyses included factors significantly associated with product choice in bivariate analyses at the $\mathrm{p}<0.2$ level. We explored possible geographic site differences in important factors by running the adjusted models by site. For factors whose relative risk ratios differed in direction and significance between the two sites, we tested for significant interaction with site at $p<0.2$. In the final model, factors associated with stated choice at $\mathrm{p}<0.05$ were considered statistically significant.

\section{Results}

Key baseline characteristics of the 277 women enrolled in TRIO are presented in Table 1. At both sites, participants' ages were evenly distributed across the age range of 18 and 30 , with a median age of 23.5. Approximately two-thirds of the sample was composed of young women aged 18-24.

Nearly all women (96\%) in Soshanguve were not married, compared with approximately half (53\%) of women in Kisumu, though the majority of women at both sites indicated currently having a primary partner $(96 \%$ in Soshanguve and $92 \%$ in Kisumu). Of women who reported having a primary partner, the median relationship duration was 3 years at both sites, with one-quarter in relationships of short duration (less than 1 year) and one-quarter in relationships of longer duration (more than 5 years). Women in Kisumu had lower educational attainment than women in Soshanguve. Parity was similar at both sites, with most women $(78 \%)$ having given birth at least once. Besides condoms, with which nearly all women had experience, the most common forms of contraception ever used among study participants were injectables $(81 \%$ in Soshanguve and $59 \%$ Kisumu), and implants (26\% in Soshanguve and $45 \%$ in Kisumu).

\section{Effect of Educational Video}

Overall, there was little change in either stated choice or product approval ratings between the pre- and post-video measurements. The only significant change was the approval of the ring, which increased by a mean of 0.35 points $(\mathrm{p}<0.001)$. Therefore, for all subsequent analyses, we selected as outcomes the measures collected after showing the video to increase standardization of basic knowledge on product dosing and use attributes.

\section{Approval Rating for Each Product: Descriptive Results}

Figure 3 presents the distribution of approval ratings on a scale of 1-5 for each product. Nearly one third (29\%) of women indicated feeling neutral about or liking/liking very much all three products, though more women $(35 \%)$ said they liked the injections very much, while women tended to give lower ratings to the ring, with $44 \%$ saying they either disliked it or disliked it very much. When rating the three products, the majority (52\%) exhibited large variation in their approval ratings across the products, with either 3 or 4 points difference between their lowest and highest rated products. Very few $(8 \%, \mathrm{n}=21)$ gave all three products the exact same rating. Of these, the majority $(n=18)$ said they liked all three products (gave a rating of 4 out of 5).

\section{Stated Choice Among the Three Products: Relationship to Influencing Factors}

Of the 277 participants, the majority (62\%, 172 women) said they would choose the injections, followed by 75 (27\%) who would choose the tablets and $30(11 \%)$ who would choose the ring. Table 2 presents characteristics hypothesized to be important influences on acceptability, by stated product choice. In these bivariate analyses, geographic site, age, worry about getting infected with HIV in the next 12 months, perceived likelihood of having an unintended pregnancy in the next 12 months, the importance of side effects, availability, frequency of use, and past use of contraceptive pills, implants/IUD, injectables, and no family planning ever were all associated with stated product choice $(p<0.2)$ from the Pearson Chi squared test. Graphs of age and the likelihood of choosing each product suggested linearity between age and product choice, with a slight inflection point at age 25 , corresponding to our chosen cut-point. No family planning ever was not included as a variable in the adjusted models due to empty cells. 
Table 1 Baseline characteristics of women participating in the Trio Study, Soshanguve, South Africa and Kisumu, Kenya, 2015-2016

\begin{tabular}{|c|c|c|c|}
\hline & Soshanguve $(\mathrm{n}=140)$ & Kisumu $(\mathrm{n}=137)$ & Overall $(\mathrm{n}=277)$ \\
\hline \multicolumn{4}{|l|}{ Age } \\
\hline Mean, median (min-max) & $23.8,23.7(18.2-30.6)$ & $23.7,23.4(18.2-30.4)$ & $23.8,23.5(18.2-30.6)$ \\
\hline $18-24$ & $92(65.7)$ & $91(66.4)$ & $183(66.1)$ \\
\hline $25-30$ & $48(34.3)$ & $46(33.6)$ & $94(33.9)$ \\
\hline \multicolumn{4}{|l|}{ Marital status } \\
\hline Legally or traditionally married & $5(3.6)$ & $65(47.5)$ & $70(25.3)$ \\
\hline Not married & $135(96.4)$ & $72(52.6)$ & $207(74.7)$ \\
\hline \multicolumn{4}{|l|}{ Highest level of education } \\
\hline Attended or completed primary school & $1(0.7)$ & $36(28.3)$ & $37(13.4)$ \\
\hline Secondary school, not complete & $53(37.9)$ & $44(32.1)$ & $97(35.0)$ \\
\hline Secondary school, complete & $64(45.7)$ & $49(35.8)$ & $113(40.8)$ \\
\hline Attended college or university & $22(15.7)$ & $8(5.8)$ & $30(10.8)$ \\
\hline \multicolumn{4}{|l|}{ Religion } \\
\hline Christian & $122(87.1)$ & $121(88.3)$ & $243(87.7)$ \\
\hline Muslim & $0(0)$ & $14(10.2)$ & $14(5.1)$ \\
\hline None & $18(12.9)$ & $2(1.5)$ & $20(7.2)$ \\
\hline \multicolumn{4}{|l|}{ Food insecurity } \\
\hline Never & $86(61.4)$ & $42(30.7)$ & $128(46.2)$ \\
\hline Rarely or sometimes & $36(25.7)$ & $72(52.6)$ & $108(39.0)$ \\
\hline Often & $18(12.9)$ & $23(16.8)$ & $41(14.8)$ \\
\hline \multicolumn{4}{|l|}{ Parity } \\
\hline Median (min-max) & $1.0(0-4)$ & $1.0(0-4)$ & $1.0(0-4)$ \\
\hline 0 & $31(22.1)$ & $30(21.9)$ & $61(22.0)$ \\
\hline 1 or more & $109(77.9)$ & $107(78.1)$ & $216(78.0)$ \\
\hline \multicolumn{4}{|l|}{ Contraceptive methods ever used ${ }^{\mathrm{a}}$} \\
\hline Male condom & $131(93.6)$ & $124(90.5)$ & $255(92.1)$ \\
\hline Female condom & $7(5.0)$ & $18(13.1)$ & $25(9.0)$ \\
\hline Pills & 33 (23.6) & $39(28.5)$ & $72(26.0)$ \\
\hline Implants & $36(25.7)$ & $62(45.3)$ & $98(35.4)$ \\
\hline Injectable & $113(80.7)$ & $81(59.1)$ & $194(70.0)$ \\
\hline IUD & $7(5.0)$ & $7(5.1)$ & $14(5.1)$ \\
\hline Diaphragm/gel & $0(0.0)$ & $2(1.5)$ & $2(0.7)$ \\
\hline Traditional/rhythm method & $1(0.7)$ & $5(3.7)$ & $6(2.2)$ \\
\hline None & $1(0.7)$ & $1(0.7)$ & $2(0.7)$ \\
\hline \multicolumn{4}{|l|}{ Current contraceptive methods ${ }^{\mathrm{a}}$} \\
\hline Male condom & $80(57.1)$ & $61(44.5)$ & $141(50.9)$ \\
\hline Female condom & $2(1.4)$ & $6(4.4)$ & $8(2.9)$ \\
\hline Pills & $9(6.4)$ & $9(6.6)$ & $18(6.5)$ \\
\hline Implants & $30(21.4)$ & $37(27.0)$ & $67(24.2)$ \\
\hline Injectable & $74(52.9)$ & $41(29.9)$ & $115(41.5)$ \\
\hline IUD & $7(5.0)$ & $4(2.9)$ & $11(4.0)$ \\
\hline Diaphragm/gel & $0(0.0)$ & $1(0.7)$ & $1(0.4)$ \\
\hline Traditional/rhythm method & $1(0.7)$ & $3(2.2)$ & $4(1.4)$ \\
\hline None & $12(8.6)$ & $17(12.4)$ & $29(10.5)$ \\
\hline \multicolumn{4}{|l|}{ Relationship status } \\
\hline Currently has primary partner & $135(96.4)$ & $126(92.0)$ & $261(94.2)$ \\
\hline Does not have primary partner & $5(3.6)$ & $11(8.0)$ & $16(5.8)$ \\
\hline
\end{tabular}


Table 1 continued

\begin{tabular}{llll}
\hline & Soshanguve $(\mathrm{n}=140)$ & Kisumu $(\mathrm{n}=137)$ & Overall $(\mathrm{n}=277)$ \\
\hline Number of partners past 30 days & & & $10(7.3)$ \\
0 & $2(1.4)$ & $106(77.4)$ & $233(84.1)$ \\
1 & $127(90.7)$ & $21(15.3)$ & $32(11.6)$ \\
More than 1 & $11(7.9)$ & $25(18.3)$ & $33(11.9)$ \\
Exchange sex ever & $8(5.7)$ & $112(81.8)$ & $244(88.1)$ \\
Yes & $132(94.3)$ & \\
No & & \\
\hline
\end{tabular}

${ }^{a}$ Does not sum to $100 \%$ as participants could indicate more than one option

Fig. 3 Approval Ratings by Product

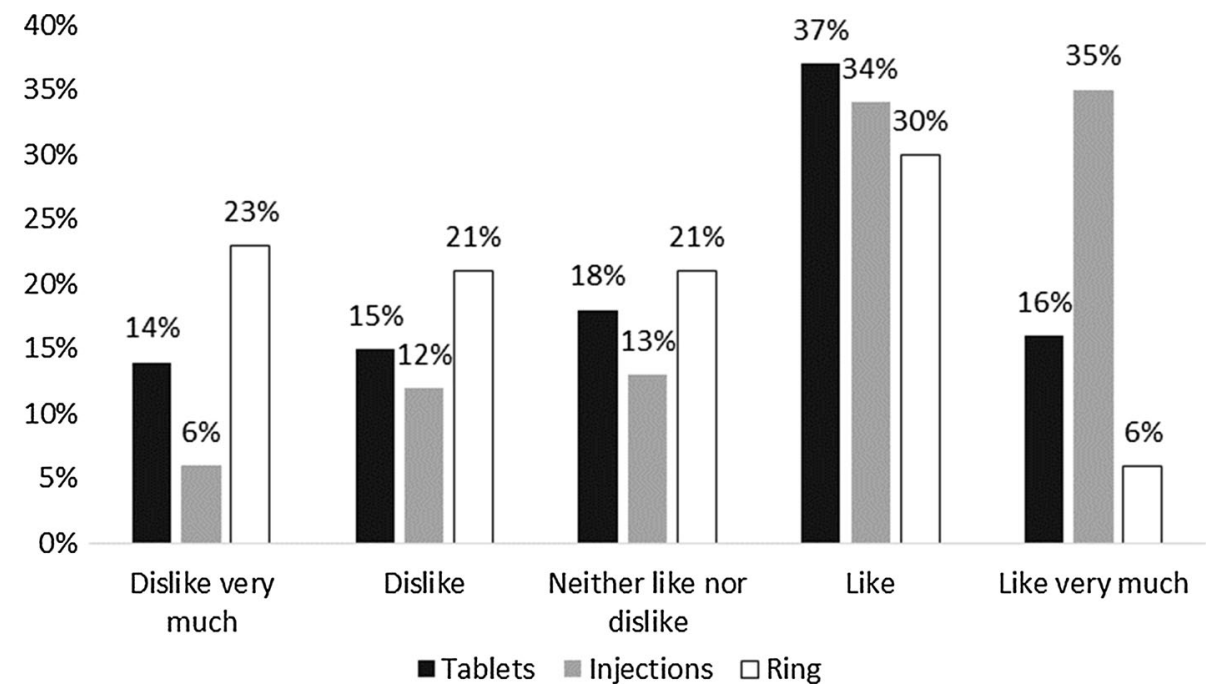

Table 3 presents results of a multinomial logistic regression analysis examining factors associated with product preference. In analyses stratified by site, there were differences in the relationship between age and product preference, though the interaction was not statistically significant, so combined results are presented in the table and those differences are described in text. HIV and pregnancy risk perception were not significantly associated with stated product choice.

Age was an important predictor of choosing the ring over the tablet, though this result was driven by age differences at the Kenya site. Overall, women aged 25-30 were three times more likely to prefer the ring over the tablet, compared to women aged 18-24 (aRRR $=3.1 ; 95 \%$ CI 1.2-8.2). In site-specific models, age was not significantly associated with product preference in Soshanguve, while in Kisumu, older women were significantly more likely to prefer the ring over the tablets (aRRR $=5.7 ; 95 \%$ CI 1.4-23.4).

Prior experience with similar contraceptive delivery forms was related to which MPT product women said they would choose. Women who had experience with contraceptive pills were more likely to prefer the tablets over the injection (aRRR $=1.9 ; 95 \%$ CI 1.0-3.7), and women who had experience with injectable contraceptives were less likely to prefer rings compared with injections (aRRR $=0.4 ; 95 \%$ CI 0.2-0.9). Women who had used long-acting reversible contraceptive methods (LARCs) (contraceptive implants or an IUD) were significantly more likely to prefer the ring over the other two products (aRRR $=3.1 ; 95 \%$ CI 1.3-7.5) compared to injections and compared to tablets (aRRR $=2.9,95 \%$ CI 1.1-7.5).

The product features that women listed as important or most important aligned with the key attributes of the product they stated they would choose. Women for whom frequency of use was an important attribute were less likely to prefer the tablets ( $\mathrm{aRRR}=0.3 ; 95 \%$ CI $0.1-0.7$ ), which has the highest dosing frequency, or the ring $(\mathrm{aRRR}=0.3$; 95\% CI 0.1-0.9), compared to the injections.

\section{Discussion}

In the baseline visit of the TRIO Study, product-naïve women in Kisumu, Kenya and Soshanguve, South Africa were asked to state their choice among three hypothetical 
Table 2 Hypothesized influencing factors and stated product choice among women participating in the Trio Study

\begin{tabular}{|c|c|c|c|c|}
\hline & $\begin{array}{l}\text { Tablets }(\mathrm{n}=75 \\
27.1 \%)\end{array}$ & $\begin{array}{l}\text { Injections }(\mathrm{n}=172 \text {; } \\
62.1 \%)\end{array}$ & $\begin{array}{l}\text { Ring }(\mathrm{n}=30 \\
10.8 \%)\end{array}$ & Pearson $X^{2} p$ value \\
\hline \multicolumn{5}{|l|}{ Sociodemographic factors } \\
\hline Age** & & & & 0.031 \\
\hline $18-24$ & $58(31.7)$ & $109(59.6)$ & $16(8.7)$ & \\
\hline $25-30$ & $17(18.1)$ & $63(67.0)$ & $14(14.9)$ & \\
\hline Highest level of education & & & & 0.334 \\
\hline Attended or completed primary school & $10(27.0)$ & $19(51.4)$ & $8(21.6)$ & \\
\hline Secondary school, not complete & $25(25.8)$ & $64(66.0)$ & $8(8.3)$ & \\
\hline Secondary school, complete & $33(29.2)$ & $68(60.2)$ & $12(10.6)$ & \\
\hline Attended college or university & $7(23.3)$ & $21(70.0)$ & $2(6.7)$ & \\
\hline Religion & & & & 0.270 \\
\hline Christian & $64(26.3)$ & $152(62.6)$ & $27(11.1)$ & \\
\hline Muslim & $5(35.7)$ & $6(42.9)$ & $3(21.4)$ & \\
\hline None & $6(30.0)$ & $14(70.0)$ & $0(0)$ & \\
\hline Worry not enough food in past 4 weeks & & & & 0.436 \\
\hline Never & $40(31.3)$ & $78(60.9)$ & $10(7.8)$ & \\
\hline Rarely or sometimes & $26(24.1)$ & $67(62.0)$ & $15(13.9)$ & \\
\hline Often & $9(22.0)$ & $27(65.9)$ & $5(12.2)$ & \\
\hline Parity & & & & 0.935 \\
\hline 0 & $16(26.2)$ & $39(63.9)$ & $6(9.8)$ & \\
\hline 1 or more & $59(27.3)$ & $133(61.6)$ & $24(11.1)$ & \\
\hline \multicolumn{5}{|l|}{ Contextual factors } \\
\hline Geographic site* & & & & 0.079 \\
\hline Soshanguve & $31(22.1)$ & 96 (68.6) & $13(9.3)$ & \\
\hline Kisumu & $44(32.1)$ & $76(55.5)$ & $17(12.4)$ & \\
\hline Number of sex partners past 30 days & & & & 0.584 \\
\hline 0 & $4(33.3)$ & $7(58.3)$ & $1(8.3)$ & \\
\hline 1 & $62(26.6)$ & $148(63.5)$ & $23(9.9)$ & \\
\hline More than 1 & $9(28.1)$ & $17(53.1)$ & $6(18.8)$ & \\
\hline Primary partner has other sex partners & & & & 0.945 \\
\hline Yes, I know & $9(25.0)$ & $23(63.9)$ & $4(11.1)$ & \\
\hline Yes, I suspect or Don't know & $41(28.3)$ & $88(60.7)$ & $16(11.0)$ & \\
\hline No & $21(26.3)$ & $52(65.0)$ & $7(8.8)$ & \\
\hline No primary partner & $4(25.0)$ & $9(56.3)$ & $3(18.8)$ & \\
\hline Exchange sex ever & & & & 0.308 \\
\hline Yes & $7(21.2)$ & $20(60.6)$ & $6(18.2)$ & \\
\hline No & $68(27.9)$ & $152(62.3)$ & $24(9.8)$ & \\
\hline \multicolumn{5}{|l|}{ Risk perception } \\
\hline Worry about HIV infection next 12 months $\dagger$ & & & & 0.181 \\
\hline Not at all/a little worried & $42(23.5)$ & $116(64.8)$ & $21(11.7)$ & \\
\hline Somewhat/very/extremely worried & $33(33.7)$ & $56(57.1)$ & $9(9.2)$ & \\
\hline Unintended pregnancy next 12 months** & & & & 0.046 \\
\hline Extremely/very unlikely & $53(24.4)$ & $143(65.9)$ & $21(9.7)$ & \\
\hline Somewhat/very/extremely likely & $22(36.7)$ & $29(48.3)$ & $9(15.0)$ & \\
\hline \multicolumn{5}{|l|}{ Product features } \\
\hline \multicolumn{5}{|l|}{ Most/second most important attribute } \\
\hline Side effects/safety $\dagger$ & & & & 0.155 \\
\hline Yes & $26(23.2)$ & $77(68.8)$ & $9(8.0)$ & \\
\hline No & 49 (29.7) & 95 (57.6) & $21(12.7)$ & \\
\hline Availability/access* & & & & 0.053 \\
\hline Yes & $23(39.7)$ & $30(51.7)$ & $5(8.6)$ & \\
\hline No & $52(23.7)$ & $142(64.8)$ & $25(11.4)$ & \\
\hline
\end{tabular}


Table 2 continued

\begin{tabular}{|c|c|c|c|c|}
\hline & $\begin{array}{l}\text { Tablets }(\mathrm{n}=75 \text {; } \\
27.1 \%)\end{array}$ & $\begin{array}{l}\text { Injections }(\mathrm{n}=172 \\
62.1 \%)\end{array}$ & $\begin{array}{l}\text { Ring }(\mathrm{n}=30 ; \\
10.8 \%)\end{array}$ & Pearson $X^{2} p$ value \\
\hline Frequency of use ${ }^{* *}$ & & & & $<0.001$ \\
\hline Yes & $7(10.9)$ & $53(82.8)$ & $4(6.3)$ & \\
\hline No & $68(31.9)$ & $119(55.9)$ & $26(12.2)$ & \\
\hline Experience with vaginal insertion & & & & 0.235 \\
\hline Yes & $26(21.9)$ & $79(66.4)$ & $14(11.8)$ & \\
\hline No & $49(31.0)$ & $93(58.9)$ & $16(10.1)$ & \\
\hline \multicolumn{5}{|l|}{ Contraceptive methods ever used } \\
\hline Male condom & & & & 0.744 \\
\hline Yes & $68(26.7)$ & $160(62.8)$ & $27(10.6)$ & \\
\hline No & $7(31.8)$ & $12(54.6)$ & $3(13.6)$ & \\
\hline Female condom & & & & 0.672 \\
\hline Yes & $6(24.0)$ & $15(60.0)$ & $4(16.0)$ & \\
\hline No & $69(27.4)$ & $157(62.3)$ & $26(10.3)$ & \\
\hline Pills $\dagger$ & & & & 0.133 \\
\hline Yes & $26(36.1)$ & $39(54.2)$ & $7(9.7)$ & \\
\hline No & $49(23.9)$ & $133(64.9)$ & $23(11.2)$ & \\
\hline Implants/IUD** & & & & 0.012 \\
\hline Yes & $25(32.1)$ & $40(51.3)$ & $13(16.7)$ & \\
\hline No & $50(25.1)$ & $132(66.3)$ & $17(8.5)$ & \\
\hline Injectable** & & & & 0.003 \\
\hline Yes & $44(22.7)$ & $133(68.6)$ & $17(8.8)$ & \\
\hline No & $31(37.4)$ & $39(47.0)$ & $13(15.7)$ & \\
\hline None* & & & & 0.066 \\
\hline Yes & $2(100.0)$ & $0(0)$ & $0(0)$ & \\
\hline No & $73(26.7)$ & $172(62.6)$ & $30(10.9)$ & \\
\hline \multicolumn{5}{|l|}{ Current contraceptive methods } \\
\hline Male condom & & & & 0.922 \\
\hline Yes & $39(27.7)$ & $86(61.0)$ & $16(11.4)$ & \\
\hline No & $36(26.5)$ & $86(63.2)$ & $14(10.3)$ & \\
\hline Female condom & & & & 0.569 \\
\hline Yes & $2(25.0)$ & $6(75.0)$ & $0(0.0)$ & \\
\hline No & $73(27.1)$ & $166(61.7)$ & $30(11.2)$ & \\
\hline Pills* & & & & 0.083 \\
\hline Yes & $7(38.9)$ & $7(38.9)$ & $4(22.2)$ & \\
\hline No & $68(26.3)$ & $165(63.7)$ & $26(10.0)$ & \\
\hline Implants/IUD** & & & & 0.040 \\
\hline Yes & $25(32.1)$ & $40(51.3)$ & $13(16.7)$ & \\
\hline No & $50(25.1)$ & $132(66.3)$ & $17(8.5)$ & \\
\hline Injectable** & & & & $<0.001$ \\
\hline Yes & $18(15.7)$ & $88(76.5)$ & $9(7.8)$ & \\
\hline No & $57(35.2)$ & 84 (51.9) & $21(13.0)$ & \\
\hline None & & & & 0.391 \\
\hline Yes & $9(31.0)$ & $19(65.5)$ & $1(3.5)$ & \\
\hline No & $66(26.6)$ & $153(61.7)$ & $29(11.7)$ & \\
\hline
\end{tabular}

Row percentages presented

$\dagger \mathrm{p}<0.20 ; * \mathrm{p}<0.10 ; *$ p $<0.05$ 
Table 3 Adjusted relative risk ratios for stated product choice among women participating in the Trio Study

\begin{tabular}{|c|c|c|c|}
\hline $\mathrm{N}=277$ & $\begin{array}{l}\text { Tablets (vs injections) aRRR (95\% } \\
\text { CI) }\end{array}$ & $\begin{array}{l}\text { Ring (vs injections) aRRR (95\% } \\
\text { CI) }\end{array}$ & $\begin{array}{l}\text { Ring (vs tablets) aRRR (95\% } \\
\text { CI) }\end{array}$ \\
\hline \multicolumn{4}{|l|}{ Site } \\
\hline Soshanguve & [ref] & [ref] & [ref] \\
\hline Kisumu & $0.90(0.40-2.03)$ & $0.49(0.15-1.63)$ & $0.55(0.15-1.98)$ \\
\hline \multicolumn{4}{|l|}{ Age } \\
\hline $17-24$ & [ref] & [ref] & [ref] \\
\hline $25-30$ & $0.57(0.29-1.12)$ & $1.74(0.73-4.15)$ & $3.07(1.15-8.17)^{* *}$ \\
\hline \multicolumn{4}{|l|}{ Worry about HIV infection } \\
\hline Not at all/a little worried & [ref] & [ref] & [ref] \\
\hline $\begin{array}{l}\text { Smwht/very/extremely } \\
\text { worried }\end{array}$ & $1.60(0.87-2.96)$ & $0.81(0.33-2.00)$ & $0.50(0.19-1.32)$ \\
\hline \multicolumn{4}{|c|}{ Unintended pregnancy next 12 months } \\
\hline Extremely/very unlikely & [ref] & [ref] & [ref] \\
\hline $\begin{array}{l}\text { Somewhat/very/extremely } \\
\text { likely }\end{array}$ & $1.46(0.72-2.96)$ & $2.08(0.79-5.47)$ & $1.43(0.51-4.00)$ \\
\hline \multicolumn{4}{|c|}{ Most/second most important attributes } \\
\hline Side effects & $0.89(0.40-1.97)$ & $0.40(0.12-1.32)$ & $0.45(0.12-1.64)$ \\
\hline Availability & $1.41(0.66-3.00)$ & $0.48(0.15-1.51)$ & $0.34(0.10-1.12)$ \\
\hline Frequency & $0.27(0.11-0.67)^{* * *}$ & $0.26(0.08-0.92)^{* *}$ & $0.99(0.23-4.22)$ \\
\hline \multicolumn{4}{|l|}{ Prior contraceptive use } \\
\hline Pills & $1.92(1.01-3.67)^{* *}$ & $0.94(0.35-2.53)$ & $0.49(0.17-1.39)$ \\
\hline Injectables & $0.52(0.27-1.01)$ & $0.38(0.16-0.94)^{* *}$ & $0.74(0.28-1.93)$ \\
\hline Implants/IUD & $1.08(0.58-2.02)$ & $3.13(1.31-7.48) * *$ & $2.88(1.12-7.45)^{* *}$ \\
\hline
\end{tabular}

$* * * \mathrm{p}<0.01, * * \mathrm{p}<0.05$

MPT delivery forms after viewing a brief standardized educational video on the three products: oral tablets, vaginal ring, and injections. They also provided their approval rating of each delivery form. The majority of women in the study indicated they would choose to use an injectable product to prevent HIV and pregnancy over oral tablets or a vaginal ring. However, the results highlight several key differences between women who preferred the injections and those-in the minority-who preferred the daily tablets or a monthly vaginal ring.

\section{Stated Choice of Injections}

Women who had used injectable contraception were more likely to indicate a stated choice for the injections relative to either the ring or the tablets, likely because their familiarity with injections influenced a preference for an injectable MPT. Women who indicated frequency of use as an important product attribute were less likely to prefer the tablets and the ring relative to the injections, which provide an advantage in terms of low frequency of use, low user burden and correct administration (by a provider) [28]. However, it is worth noting that a much higher proportion of participants reported having ever used injectable contraception than were currently using the method (70\% vs. $42 \%$ ), indicating they had discontinued or switched away from this method of family planning. Many women switch or discontinue use of contraceptive methods due to side effects, contextual factors, and other reasons [29, 30] that our study was not able to incorporate given the hypothetical nature of the MPT product and our focus on acceptability of the delivery form, and not the $\operatorname{drug}(\mathrm{s})$ they may eventually contain.

\section{Stated Choice of Tablets}

About a quarter of the women in the TRIO Study indicated they would choose the oral tablets for HIV and pregnancy prevention. The main predictor of choosing tablets over injections was prior use of pills for contraception, as these women have experienced having to take a pill every day and may also have been successful in the past at daily pill taking. Though most of the TRIO participants had likely experienced taking oral medication tablets at some point in their lives, the daily dosing requirement as a prevention behavior sets oral PrEP apart from daily oral dosing to treat 
a disease. In addition, the Truvada pill's large size and its resemblance to an $\mathrm{ARV}$ and the associated potential for stigma, concerns that have been expressed by women in other studies [31, 32], may have decreased interest in this delivery form.

\section{Stated Choice of the Ring}

Overall, of the three delivery forms evaluated in the TRIO Study, the vaginal ring was the most novel, the contraceptive Nuvaring having been recently introduced with very low coverage in South Africa [33] and used only in a demonstration study in Kisumu [34]. It was also the least popular product among young women at the baseline visit. Notably, the ring is the most advanced co-formulated MPT in the product development pipeline, so particular emphasis should be given to ways to improve its future acceptability.

Women age 25 and above were three times more likely to prefer the ring than women under 25. This finding aligns with results from the ASPIRE vaginal ring trial, where younger women exhibited lower adherence to the ring relative to older women [18]. The association was driven by data from the Kisumu site, though we suspect the site difference may be due to very few women overall preferring the ring in Soshanguve. Older women may have more stable relationships and therefore may be more willing to disclose the ring to their partners, which may be perceived as the most difficult of the three product to use secretly. Regarding disclosure, women in a mixed methods study of vaginal ring acceptability in South Africa have expressed that married women should disclose product use, but that casual partners could use a product in secret [35]. Of note, more women in Kisumu were married than in Soshanguve, so marital status may have played a role in the site difference.

Women who had used implants or an IUD for contraception were more likely to prefer the ring than their counterparts who had never used those LARCs, which currently have limited provision in SSA [36], although implant use was high in our study population. Women who adopted these methods may represent early adopters of new health technology, and may be more willing to use other novel technologies like the ring. Women who have selected implants or IUDs as a family planning method may also be more comfortable with using a device that remains inside the body for an extended time period. These results highlight the importance of familiarity in selecting a novel product, echoing previous findings from studies that have introduced vaginal rings. Indeed, in qualitative work conducted as part of the ASPIRE ring trial, the majority of women participating in in-depth-interviews at the exit visit, with 12-33 months of experience using the ring, preferred the ring among eight HIV prevention products discussed.
Familiarity was cited by these participants as a key reason for this preference [37]. A study in Australian women predicted that the vaginal contraceptive ring, a novel product that had not yet been introduced in that country, would only capture $3 \%$ of the contraceptive market share [38] based on a survey that described the product. However, in trials of the contraceptive ring in Europe and North America, familiarity was an important predictor of method preference, with $81 \%$ of women perceiving the ring as the best contraceptive method after 3 months of use, in contrast to $66 \%$ perceiving the tablet as the best method at baseline [39].

\section{Limitations and Future Research Directions}

Investigating factors related to preference for the less popular products, particularly the ring, was limited by a small sample size of women who selected this as their preferred product at baseline. In addition, a quantitative study may not fully capture nuanced reasons for product choice, particularly in terms of likes and dislikes of various product attributes. At baseline, we collected what women stated they would choose, but did not assess the reason(s) for their stated choice. Comprehensive data examining MPT acceptability and product preference, including several rounds of qualitative interviews and focus groups in the TRIO Study during follow-up will permit in-depth analysis of women's preferences and use experiences.

A major limitation of the TRIO Study's ability to draw conclusions about potential uptake of real products is the hypothetical nature of the MPT products. The goal of TRIO was to gather information about acceptability of each delivery form, separate from the active medications that they may eventually contain, but this separation leaves out details that could be important influencers of product preference and uptake. Importantly, the two-injection regimen used in TRIO is significantly simpler than that of the current long-acting injection in phase II that requires leadin and lead-out dosing of oral PrEP [19], and we did not assess the likely significant impact of this requirement on potential acceptability. In addition, participants were given no information about the possible side effects of each product. Nevertheless, we feel our findings are still informative as the study mimics a real-world scenario in which potential end users are briefly informed about three options and must make a choice, without necessarily having complete information or understanding. Subsequent analysis of prospective data from TRIO will allow us to evaluate whether these preferences shift after opportunities to actually use the products, and to explore the factors influencing any changes observed.

Finally, the role of health care providers and other key informants in product roll-out and uptake cannot be 
ignored [40, 41], so perspectives of these key informants should also be incorporated into overall decisions about product development and messaging.

\section{Implications for MPT Research and Development}

These results provide a strong case for capitalizing on the acceptability and high uptake of existing contraceptive delivery forms in developing acceptable MPT products. Research will need to identify ways to increase familiarity of women with novel delivery forms, such as the ring, to improve uptake and consistent use in effectiveness trials. Enhanced ring messaging will be needed to engage endusers, particularly younger women in trying this unfamiliar method, which was the least popular of the three delivery forms in this study. Strategies in oral MPT tablet research should incorporate simple strategies to decrease the burden of daily dosing.

Acknowledgements Funding for this study was supported by the Bill \& Melinda Gates Foundation (OPP1114942). The authors would particularly like to thank the Trio Study participants for contributing their time and providing valuable input.

\section{Compliance with Ethical Standards}

Conflict of interest The authors declared that they have no conflict of interest.

Ethical Approval All procedures performed in studies involving human participants were in accordance with the ethical standards of the institutional and national research committee and with the 1964 Helsinki declaration and its later amendments or comparable ethical standards.

Informed consent Informed consent was obtained from all individual participants included in the study.

Open Access This article is distributed under the terms of the Creative Commons Attribution 4.0 International License (http://crea tivecommons.org/licenses/by/4.0/), which permits unrestricted use, distribution, and reproduction in any medium, provided you give appropriate credit to the original author(s) and the source, provide a link to the Creative Commons license, and indicate if changes were made.

\section{References}

1. Joint Programme on HIV/AIDS (UNAIDS). The Gap Report. Geneva, Switzerland 2014. http://www.mccza.com/documents/ 2e4b3a5310.11_Media_release_ARV_FDC_PrEP_Nov15_v1.pdf. Accessed Aug 292017.

2. MacPhail C, Pettifor A, Pascoe S, Rees H. Contraception use and pregnancy among 15-24 year old South African women: a nationally representative cross-sectional survey. BMC Med. 2007;5:31.

3. Kott A. Rates of unintended pregnancy remain high in developing regions. Int Perspect Sex Reprod Health. 2011;37(1):46-7.

4. Mayondi G, Wirth K, Morroni C, Moyo S, Ajibola G, Diseko M, et al. Unintended pregnancy, contraceptive use, and childbearing desires among HIV-infected and HIV-uninfected women in Botswana: across-sectional study. BMC Public Health. 2016;16:44.

5. Mukiira C, Mumah J, Kabiru CW, and Izugbara C. Unintended pregnancy by the numbers: a look at Kenya, STEP UP Fact Sheet. Nairobi: African Population and Health Research Center. 2014. https://www.popcouncil.org/uploads/pdfs/2014STEPUP_UPFact Sheet.pdf. Accessed Aug 292017.

6. Seutlwadi L, Peltzer K, Mchunu G, Tutshana B. Contraceptive use and associated factors among South African youth (18-24 years): a population-based survey. SAJOG-S Afr J Obstet. 2012;18(2):43-7.

7. Performance Monitoring and Accountability 2020 (PMA2020) Project ICF, (ICRHK) RHK. Detailed Indicator Report: Kenya 2014. Baltimore, MD 2014. https://pma2020.org/sites/default/ files/PMAKE-DIR-2015.04.27_2_0.pdf. Accessed Aug 292017.

8. Corneli A, Perry B, McKenna K, Agot K, Ahmed K, Taylor J, et al. Participants' explanations for nonadherence in the FEM-PrEP clinical trial. J Acquir Immune Defic Syndr. 2016;71(4):452-61.

9. van der Straten A, Stadler J, Montgomery E, Hartmann M, Magazi $\mathrm{B}$, Mathebula F, et al. Women's experiences with oral and vaginal pre-exposure prophylaxis: the VOICE-C qualitative study in Johannesburg, South Africa. PLoS ONE. 2014;9(2):e89118.

10. Tolley E, Morrow K, Owen D. Designing a multipurpose technology for acceptability and adherence. Antiviral Res. 2013;100(Suppl):S54-9.

11. Mensch B, van der Straten A, Katzen L. Acceptability in microbicide and PrEP trials: current status and a reconceptualization. Curr Opin HIV AIDS. 2012;7(6):534-41.

12. Corneli A, Deese J, Wang M, Taylor D, Ahmed K, Agot K, et al. FEM-PrEP: adherence patterns and factors associated with adherence to a daily oral study product for pre-exposure prophylaxis. J Acquir Immune Defic Syndr. 2014;66(3):324-31.

13. Celum C, Baeten J. Tenofovir-based pre-exposure prophylaxis for HIV prevention: evolving evidence. Curr Opin Infect Dis. 2012;25(1):51-7.

14. Brown E, Palanee-Philips T, Marzinke M, Hendrix C, Dezutti C, Soto-Torres L, et al. Residual dapivirine ring levels indicate higher adherence to vaginal ring is associated with HIV-1 protection. Presented at 21st International AIDS Conference, 2016 July 28-22, Durban, South Africa.

15. Heise L. Beyond acceptability: reorienting research on contraceptive choice. 1997. In: Beyond acceptability: reorienting research on contraceptive choice. London: Reproductive Health Matters for the World Health Organization; [6-14]. http:// whqlibdoc.who.int/publications/0953121003.pdf. Accessed Aug 292017.

16. Magadi MA, Curtis SL. Trends and determinants of contraceptive method choice in Kenya. Stud Fam Plann. 2003;34(3):149-59.

17. Nel A, Bekker LG, Bukusi E, Hellstrm E, Kotze P, Louw C, et al. Safety, acceptability and adherence of dapivirine vaginal ring in a microbicide clinical trial conducted in multiple countries in SubSaharan Africa. PLoS ONE. 2016;11(3):e0147743.

18. Baeten JM, Palanee-Phillips T, Brown ER, Schwartz K, SotoTorres LE, Govender V, et al. Use of a vaginal ring containing dapivirine for HIV-1 prevention in women. $\mathrm{N}$ Engl $\mathrm{J}$ Med. 2016;375(22):2121-32.

19. HIV Prevention Trials Network. Phase II Safety and Acceptability of an Investigational Injectable Product, TMC278 LA, for Pre Exposure Prophylaxis (PrEP), 2016.https://www.hptn.org/ research/studies/152. Accessed Aug 292017.

20. Press Release: Medicines Control Council approves fixed-dose combination of tenofovir disoproxil fumarate and emtricitabine for pre-exposure prophylaxis of HIV. 2015 http://www.mccza.com/ documents/2e4b3a5310.11_Media_release_ARV_FDC_PrEP_Nov 15_v1.pdf. Accessed Aug 292017. 
21. Ministry of Health National AIDS and STI Control Programme. Guidelines on use of antiretroviral drugs for treating and preventing HIV infection in Kenya. Nairobi, Kenya: NASCOP; 2016.

22. HPTN 076 Protocol Final v3.0, 2016 https://www.hptn.org/sites/ default/files/2016-05/HPTN\%20076\%20Protocol\%20Final\%20v3. 0,\%204Apr2016.pdf. Accessed Aug 292017.

23. MTN-020 Protocol 2011. http://www.mtnstopshiv.org/sites/default/ files/attachments/MTN-020\%20Version1\%200_28September2011_ CLEAN.pdf. Accessed Aug 292017.

24. Montgomery ET, Mensch B, Musara P, Hartmann M, Woeber K, Etima J, et al. Misreporting of product adherence in the MTN003/VOICE trial for HIV prevention in Africa: participants' explanations for dishonesty. AIDS Behav. 2017;21(2):481-91.

25. Weiser SD, Young SL, Cohen CR, Kushel MB, Tsai AC, Tien $\mathrm{PC}$, et al. Conceptual framework for understanding the bidirectional links between food insecurity and HIV/AIDS. Am J Clin Nutr. 2011;94(6):1729s-39s.

26. Anema A, Vogenthaler N, Frongillo EA, Kadiyala S, Weiser SD. Food insecurity and HIV/AIDS: current knowledge, gaps, and research priorities. Curr HIV/AIDS Rep. 2009;6(4):224-31.

27. United Nations Educational Scientific and Cultural Organization. Youth-Definition 2016 http://www.unesco.org/new/en/socialand-human-sciences/themes/youth/youth-definition/. Accessed Aug 292017.

28. Lucas J, El-Sahn M. MPT Acceptability in Uganda, Nigeria and South Africa: understanding the women, The End User [Webinar]. 2014.

29. Wulifan JK, Brenner S, Jahn A, De Allegri M. A scoping review on determinants of unmet need for family planning among women of reproductive age in low and middle income countries. BMC Womens Health. 2016;16:2.

30. Jain AK, Winfrey W. Contribution of contraceptive discontinuation to unintended births in 36 developing countries. Stud Fam Plan. 2017;48(3):269-78.

31. Minnis AM, Gandham S, Richardson BA, Guddera V, Chen BA, Salata R, et al. Adherence and acceptability in MTN 001: a randomized cross-over trial of daily oral and topical tenofovir for HIV prevention in women. AIDS Behav. 2013;17(2):737-47.

32. Luecke EH, Cheng H, Woeber K, Nakyanzi T, MudekunyeMahaka IC, van der Straten A, et al. Stated product formulation preferences for HIV pre-exposure prophylaxis among women in the VOICE-D (MTN-003D) study. J Int AIDS Soc. 2016;19(1):20875.

33. United Nations Department of Economic and Social Affairs Population Division. Trends in Contraceptive Use Worldwide 2015. http://www.un.org/en/development/desa/population/publications/ pdf/family/trendsContraceptiveUse2015Report.pdf. Accessed Aug 292017.

34. Study of nuvaring acceptability, adherence and biological effects among HIV-negative women in Kenya 2015. https://clinicaltrials. gov/ct2/show/NCT02529683. Accessed Aug 292017.

35. van der Straten A, Montgomery ET, Cheng H, Wegner L, Masenga G, von Mollendorf C, et al. High acceptability of a vaginal ring intended as a microbicide delivery method for HIV prevention in African women. AIDS Behav. 2012;16(7):1775-86.

36. Morse J, Chipato T, Blanchard K, Nhemachena T, Ramjee G, McCulloch $\mathrm{C}$, et al. Provision of long-acting reversible contraception in HIV-prevalent countries: results from nationally representative surveys in southern Africa. BJOG. 2013;120(11):1386-94.

37. van der Straten A, Shapley-Quinn M, Reddy K, Cheng H, Etima J, Woeber K, et al. HIV PrEP Formulation Preference Among Women in the Qualitative Component of the MTN-020/ASPIRE Study. Presented at 21st International AIDS Conference, 2016 July 28-22, Durban, South Africa.

38. Fiebig DG, Knox S, Viney R, Haas M, Street DJ. Preferences for new and existing contraceptive products. Health Econ. 2011;20:35-52.

39. Novak A, de la Loge C, Abetz L, van der Meulen EA. The combined contraceptive vaginal ring, NuvaRing (R): an international study of user acceptability. Contraception. 2003;67(3):187-94.

40. Delany-Moretlwe S, Mullick S, Eakle R, Rees H. Planning for HIV preexposure prophylaxis introduction: lessons learned from contraception. Curr Opin HIV AIDS. 2016;11(1):87-93.

41. Mantell JE, West BS, Sue K, Hoffman S, Exner TM, Kelvin E, et al. Health care providers: a missing link in understanding acceptability of the female condom. AIDS Educ Prev. 2011;23(1):65-77. 